\title{
User-based Furniture Recycling System Innovation and Its
}

\section{Implementation}

\author{
Shangguan $\mathrm{LI}^{1,2, a}$, Ming $\mathrm{CHEN}^{1,2, \mathrm{~b},{ }^{*},}$ Jianhua $\mathrm{LYU}^{1,2, \mathrm{c}}$ \\ ${ }^{1}$ Forestry College, Sichuan Agricultural University, Chengdu 611130, China \\ ${ }^{2}$ Key Laboratory of Wood Industry and Furniture Engineering, Sichuan Agricultural University, \\ Chengdu 611130, China \\ aleeshanga@foxmail.com, ${ }^{\text {b }}$ chenming@sicau.edu.cn, ${ }^{9}$ ljh@sicau.edu.cn
}

${ }^{*}$ Corresponding author

Key words: furniture; recycling system; service design; innovation

Abstract: The increasing level of material life has accelerated the speed of the upgrading of the furniture industry products. However, the idea of green ecology and sustainable development has been advocated by more and more people. Therefore, furniture recycling design will be the future development trend of the furniture industry, building a high efficient and rational design of the furniture recycling system is imperative. At present, the use of reverse logistics theory, recycling technology and furniture components reuse to research furniture design system is mostly, however, the research on furniture circulation based on service design is less. Therefore, this article from the perspective of design, bases on service design idea of "take the customer as the center", proposes furniture design cycle system should adhere to the "product + service" point of view, and analyzes the application of Quality Function Deployment (QFD) in the circulation system of furniture design. And from the perspective of the user experience, combining with the current recycling of furniture products, the article analyzes the feasibility and advantages of the introduction business model in electronic commerce, describes the process of the furniture recycling system based on the Internet. Finally, the methods of strengthening service content and improving the competitiveness of furniture circulation system are discussed in the end.

\section{Introduction}

In the industrial age, the demand for furniture was greater than the supply, therefore, the design, development, production and selling of products were manufacturer driven [1] to realize the values of the products on the users. With the arrival of service economy age, the users-based production and services are becoming more important. Nowadays, the individualized needs of customers are increasing, and there are more consumers who like vintage and cost effective furniture; However, despite the current social situation of natural resource shortage, furniture are deemed out dated in four to five years compared with several decades in the past, and large amount of out-dated furniture is becoming new social issue; taking Beijing as an example, data shows that over one million sets of furniture are abandoned in 2009 [2]. Therefore, furniture recycling system innovative thinking and method study have active practical significance, and implementation of which will benefit both the present society and the future. 


\section{Furniture Recycling System and Service Design}

The research of furniture recycling system is aimed at the systematic recycling and sustainability of furniture. The complete cycle of furniture shall be from raw material processing, product production and selling, being used by consumers to being unused or abandoned, and finally being re-used through recycling, which makes another cycle begin [3]. Relatively speaking, the recycling of furniture underlines the "physical recycling" [4], and needs more complete system to ensure efficient and feasible recycling. However, current researches mostly are based on the theory of reverse logistics and regeneration techniques [5,6], and few of them focuses on service design, therefore, limited number of innovative and scientific methods are brought out.

\section{Particularity of Furniture Recycling Design System}

The building of furniture recycling system has certain particularities compared with other cyclic design systems.

\section{Users}

in this system, users of both buyer and seller are contained, and information delay and messiness during the communication between the seller and buyer in traditional secondhand furniture market caused ineffective recycling.

\section{Service content}

the realizations of communication and exchange of furniture products are covered in this system, i.e. what kind of furniture will be provided and by which way the furniture will be exchanged. In other words, the principle of "product + service" shall be adhered to in the building of the system. Although secondhand furniture are sold and bought on part of secondhand goods trading websites [7], relevant professional services like re-design and repair are not covered, which cause less attention by users and poor sustainability.

\section{Satisfaction evaluation}

users' satisfaction toward product actually means that their expectations on the performance of the product after certain time and money are cost are met [8]. Therefore, high quality and perfect services are the keys to improve the satisfaction of users. However, the current recycling channels of furniture lack professional classification and repair, explicit pricing standard and rich service contents.

\section{Dual goals}

dual goals of recycling and recreation of commercial value shall be realized through the establishing of the furniture recycling system, therefore, both social benefits and commercial profits shall be attached importance to ensure the sustainability of the system.

\section{Re-design value}

the re-design of furniture shares similarities with green furniture design and regenerative design, that is all of them attach importance to environment protection and resource saving [9]. Embodiment of re-design value is the essential requirement of recycling system to meet the individualized demands of users and promote the sustainable development of the system.

\section{Introduction of service design}

Service design is a user-based initiative and strategic design philosophy that can meet consumer demands, improve users' satisfaction to achieve all-around service, clear procedure and efficiency and orderedness [10]. The design focus of the traditional furniture recycling system is on "things", i.e. the product itself, while service design broadens the concept of "things" and caters to the 
furniture recycling system principle of harmonious relation between "things" and "human", i.e. combination of product (visible) and service (invisible) [2]. "users-centered" is one of features of service design, thus, the user-based "product + service" philosophy becomes persistent principle of furniture recycling system. In this era when market competitiveness determine success or failure, "service" becomes a new competitive tool [11].

\section{Application of Quality Function Deployment Module}

Users' need is the first to be met in the user-based furniture recycling system to optimize service content and improve users' satisfaction and realize the dual goals and re-design value of the system. Users' need in this system is classified into two parts, i.e. buyer's need and seller's need. Adoption of scientific method to learn users' needs helps to build reasonable and efficient furniture recycling design system.

Concept of Quality Function Deployment originated in Japan in the late 1960s. In 1967, a Japanese scholar named Akao proposed Quality Function Deployment (QFD) for product development that enables precise analysis of consumers' needs $[12,13,14]$. With the deepening of research, this method affects service design research greatly, and is used by many scholars in the analysis of consumer needs and service elements. This method focuses on the invisible service itself and converts the consumers' needs into house of quality model and answers the question of "what to do" during the actual practice of service design. As shown in Figure 1, this method can also be used in the building of furniture recycling design system and has excellent operability.

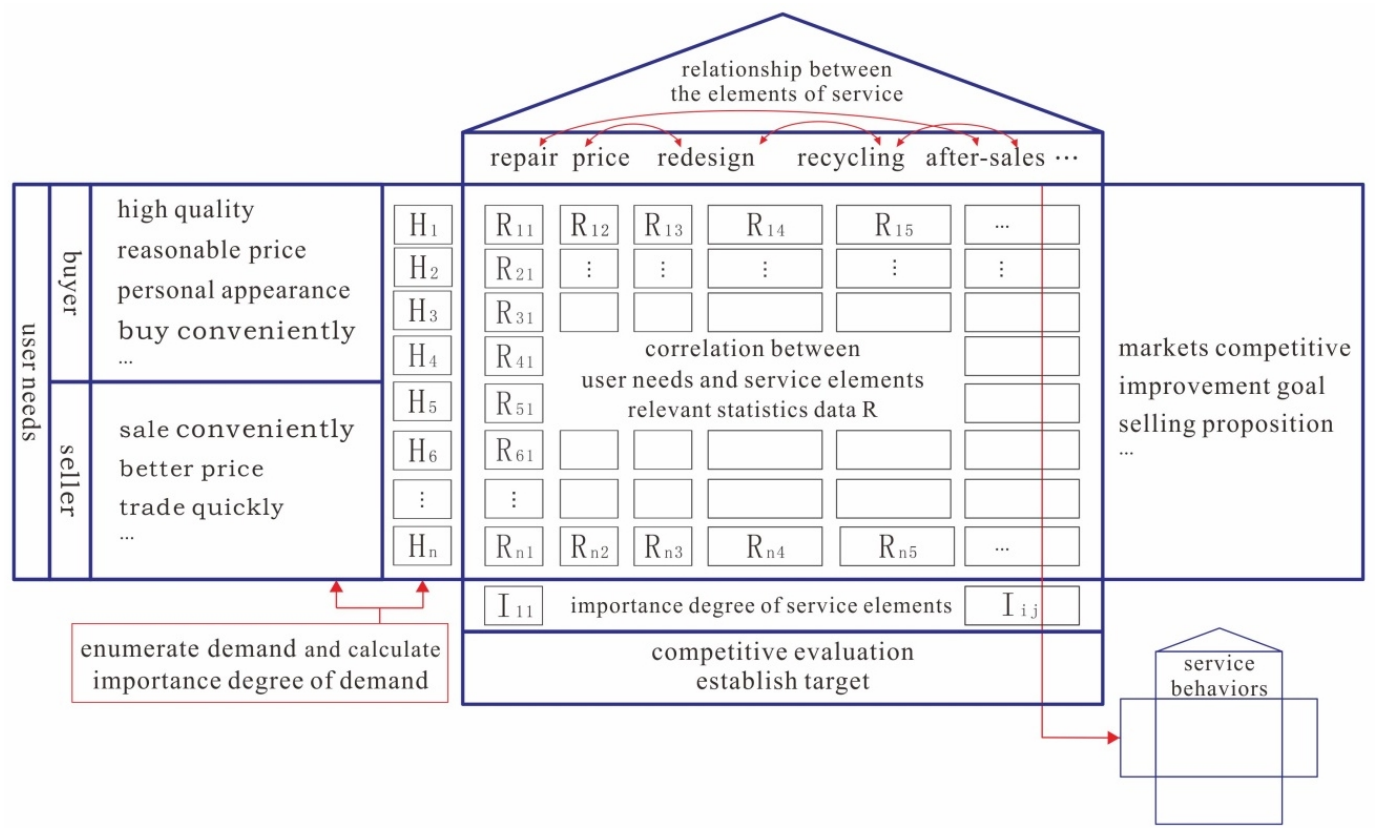

Fig.1 House of quality of the furniture recycling system

Figure 1 shows the house of quality of the furniture recycling system . The house combine with five parts as follows.

Left wall: the left wall of the house of quality is the input part, i.e. user needs, this part reflects buyers' and sellers' needs in the furniture recycling system, including furniture quality, appearance, purchase channel and price etc. Consumers' needs are the basic inputs of the quality house, which can be concluded from questionnaire survey and in-depth interview; in addition, quantitative statistics $\mathrm{H}$ of importance degree of perceptual indicators can be carried out for calculation of 
service elements importance degree. For example, demand on recycling furniture can be collected from users through interview, and such demand will be analyzed and summarized to carry out questionnaire surveys on enough number of respondents and finally to get the importance degree of demand through mathematical statistics.

Ceiling: the ceiling of house of quality represents technical elements of service, i.e. the required service items to meet the needs of both the buyer and seller, including furniture repair, pricing, re-design, recycling and after-service etc. Elements are determined by core team members of system construction through comprehensive analysis and summarizing of market survey results. Service elements can also be used as left wall input and for service behaviors in system and construction of backend system quality house.

Room: the correlation between user needs and service elements and relevant statistics data $\mathrm{R}$ can be observed directly through quality house, which enables a more direct observation on whether the services provided for users are complete.

Roof: it is possible that various services are related, which is directly expressed by roof and makes it convenient to analyze globally. As shown in Figure 1, interaction between pricing and re-design and correlation between initiative recycling and home delivery service are found. Furniture repair is also part of the after-sales service.

Right wall: right wall of quality house is market competitiveness evaluation matrix, in which line number is in one-to-one correspondence to user needs. The core team members of furniture recycling system describe some need markets competitive evaluation, improvement goal, selling proposition etc. by this matrix.

Floor: it is the important description for calculation, competitive analysis and target value of service technical elements. In the construction of furniture recycling system, core team shall calculate the Importance Degree I of service element based on the Importance Degree of User Need H and Room Number $\mathrm{R}$ as shown in Table 2. Comparison and analysis of service element with competitors are enabled to plan and establish target value.

Tab.1 Importance degree of service elements

\begin{tabular}{|c|c|c|c|c|}
\hline user needs & $\begin{array}{c}\text { importance degree of } \\
\text { user needs }\end{array}$ & element of service $E_{11}$ & $\cdots$ & element of service $E_{i j}$ \\
\hline 1 & $\mathrm{H}_{1}$ & $\mathrm{R}_{11}$ & \multirow{5}{*}{$\cdots$} & $\mathrm{R}_{1 \mathrm{~m}}$ \\
\hline 2 & $\mathrm{H}_{2}$ & $\mathrm{R}_{21}$ & & $\mathrm{R}_{2 \mathrm{~m}}$ \\
\hline 3 & $\mathrm{H}_{3}$ & $\mathrm{R}_{31}$ & & $\mathrm{R}_{3 \mathrm{~m}}$ \\
\hline$\vdots$ & $\cdots$ & . . & & . . \\
\hline $\mathrm{n}$ & $\mathrm{H}_{\mathrm{n}}$ & $\mathrm{R}_{\mathrm{n} 1}$ & & $\mathrm{R}_{\mathrm{nm}}$ \\
\hline importance deg & f service elements & $\mathrm{I}_{11}$ & $\cdots$ & $I_{i j}$ \\
\hline
\end{tabular}

Importance degree of service elements $\mathrm{I}_{\mathrm{ij}}=\sum \mathrm{H}_{\mathrm{n}} \mathrm{R}_{\mathrm{nm}}$

After the construction of quality house model, it can be perfected and supplemented based on practical feedback, which makes it possible to provide important basis for analyzing and establishing a more accurate service behavior, back-end system of quality house model.

\section{Innovation of Business Model}

In China, traditional second-hand furniture market is kind of offline entities operation with high operating costs, and the problem of slow information updating leading to the inefficiency of recycle and re-selling; Business is relatively scattered without professional recycling classification, 
evaluation, maintenance, redesign and other professional service ability. The quality of furniture is hard to be guaranteed, and individual needs of user to buy old furniture are hard to be satisfied. There is the cost pressure for some non-governmental organizations and environmental protection agency recycling only valuable solid wood furniture and rare wood furniture. As for users, achieving of easy selling or buying of idle and eliminated furniture and buying of cost effective unique second-hand furniture are the goal of the construction of furniture recycling design system.

With the development of internet technology and the prevailing of shopping online, means of buying furniture products are also changing and leading the transformation of service mode of various industries. With the help of network platform, many furniture enterprises carry out B2C (Business to Customer) in online sales business [15] and gain a good management efficiency. Offline circulation of transportation and product and online circulation of cash and information are seen on more and more mature $\mathrm{O} 2 \mathrm{O}$ business models [16]. Relying on the quick and precise information transmission, mature technology, higher consumer trust, conforming to the modern lifeway and other advantages, the above business models contribute to the innovation of furniture recycling design system and give full expression to the features to stress user experience.

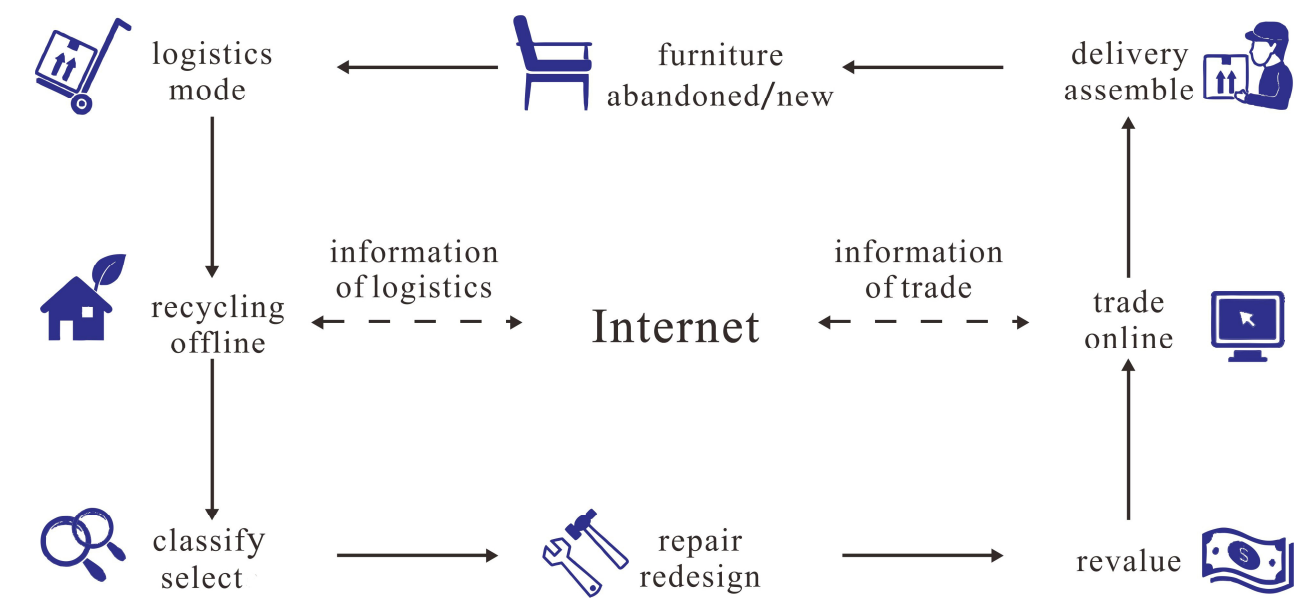

Fig.2 Process of the furniture recycling system based on the Internet

As shown in Figure 2, "furniture" refers to the combination of secondhand furniture and furniture in obtained by consumers through trading. Secondhand furniture is recycled through powerful modern logistic network, and then classified and selected by organizations specially established before being repaired or re-designed and re-evaluated for on-line trading, and finally is re-sold to the consumers. The system not only covers the trading relation between buyer and seller, but also the relation between professional services provider and the buyer \& seller, also, modern logistic system and trading are required to realize the commodity and fund circulation. Building furniture recycling design system with the help of the internet technology and mature e-commerce business model can better solve relationships among users and establish operation platform, also help the establishment of back-end service institution and design of the service behavior. In the system, furniture recycling, classification, repair, re-design, transportation and installation are completed by professional enterprises, which is called $\mathrm{B} 2 \mathrm{C}$ business. In addition, the system can integrate traditional recycling channels and modern logistics network to realize combination of online transaction and offline service (O2O, Online to Offline). Through this system, many existing problems in the current furniture recycling design system can be effectively solved for it can not only provide professional services that meet consumers' needs of high-quality and individualized furniture, but also integrate resources to enhance market competitiveness. 


\section{Enhancement of Service}

The furniture recycling system is comprehensively analyzed centering on users, service philosophy, contact point and value-added services in service design [17] to advocate transformation from resource intensive system to service intensive system. Enhancement of service is the key part in improving users' satisfaction and promoting virtuous development of the system, and it is composed of the following three parts:

\section{Value-adding of Services}

Added value can not only bring higher profit for product but also make products more popular. The furniture recycling system covers the value adding of the product itself and also the new value brings about by the service. Therefore, providing re-design service of recycled furniture for users is the key part in the system. Meanwhile, active recycling, convenient transportation and environmental disposing of wastes also embodies value-adding concept.

\section{Perfection of Service Details}

The perfection of service details mainly focuses on the optimization of service process and service contact point design. In the systemized service design, the service contact point is generated at the very moment of service providing [17]. The contact point connects the user experience end and service system back end, and the good service contact design enables understanding and guiding of users' behavior and enhances consumers' experience. For example, a good out-of-the-box experience of a product bought online by the user can not only impress the user at first sight but also embody service value adding.

\section{Optimization of Service Environment}

New furniture recycling design system is bound to impact the old system, and influence the interactions among people, product and environment and form a new service environment pattern gradually. It needs various supports from the society and gradual integration of the current furniture recycling service system to realize overall optimization and upgrading of the service environment, and help the sustainable development of the circular economy.

\section{Conclusion}

This research lays particular emphasis on the basis of furniture recycling design system method and application, and adopts the model of quality function deployment with qualitative and quantitative combination to analyze user needs and give instruction to system construction to realize the conversion of user needs and service elements. Relying on the modern e-commerce business model, it describes the furniture recycling design process based on the network platform and analyzes and concludes the reinforcement of service contents to provide the theoretical direction for innovative construction of system. The innovation of furniture recycling service system embodies "user-based" service design concept and also caters to the rise of the modern service economy, and needs long-term practice, conclusion and continuous improvement. It is necessary to employ social resources in circulation service system with abroad involved fields, including logistics, product design, processing and manufacturing and environmental protection etc., which contributes to integrating and upgrading of traditional industry to service industry. Meanwhile, value assessment, technical method for old furniture repair, network platform construction and other problems are not discussed and researched deeply, which needs constant exploration in the process of the future research. 


\section{Acknowledgements}

This project is supported by Modern Design and Culture Research Center of Sichuan Provincial Key Research Base of Philosophy and Social Sciences (Grant No. MD15E017) and the Open Research Subject of Research Base of Industrial Design Industry Research Center (Grant No. GY-15ZD-01) .

\section{Reference:}

[1] Dong Li, Xinguo Ming, Fanbin Kong, Hanxin Wang, Pengpeng Wang: A Preliminary Study on Service Design, Machine Design and Research, Vol.24,No.6, (2008), p. 6-10.

[2] Shu Wang: Funiture Redesign Platform Study Based on Service Design, Shanghai Jiao Tong University(2014).

[3] Yuxin Wang: Life Cycle Design of Furniture, Central South University of Forestry and Technology(2012).

[4] Zheng Shen: New Vision of Product Redesign , Explore the Concept,p.35-37.

[5] Feng Liu: Reverse Logistics Mode Selection and Network Construction in Furniture Manufacturing Industry, Central South University of Forestry and Technology(2012).

[6] Ran Xu: Based on component reuse renewable furniture design research, Central South University of Forestry and Technology(2012).

[7] Information on http://ya.58.com/ershoujiaju/

[8] Xiaoguang Luo: Research on Customer Satisfaction Evaluation Based on Customer Post-purchase Behavior, Harbin Engineering University (2006).

[9] Tingting Du: the Study on Regenerative Design of the Product Packaging Refuse, Shen Yang Institute of Aeronautical Engineering(2009).

[10] Bin Du: Based on Organic Farms Service Design and Brand Strategy Research, Hunan University of Technology (2014).

[11] Zhi Xu, Zunbin Fu: the Four Factors of Affecting Service Design and the Correlative Analysis , Logistics Engineering and Management, Vol.32,No.8, (2010), p. 162-170.

[12] Weijuan Zou: A Service Design Method Research Based on QFD, Hunan University (2012).

[13] Yoji A.: Quality Function Deployment: Integrating Customer Requirements into Product design. Cambridge, Massachussetts: Productivity Press(1990).

[14] Yoji A.: the Leading Edeg in QFD: Past, Present and Future, International Journal of Quality \& Reliability Management, Vol. 20,(2003), p.20 - 35.

[15] Mingliang Li: Research on Quality of Service Evaluation in B2C Electronic Commerce Based on QFD, Hebei University of Technology (2012).

[16] Yixiang Chu: Research on Operation Mode of Furniture Industry Based on the O2Omode, Hefei University of Technology (2013).

[17] Ke Yin: User-based Service Design Innovation and Its Implementation, Packing Engineering, Vol.36,No.2, (2015), p. 9-12. 